\title{
Guangxi cobra venom-derived NGF promotes the osteogenic and therapeutic effects of porous BCP ceramic
}

\author{
Pan Jin ${ }^{1,2,3,6}$, Fuqiang Yin ${ }^{4,6}$, Li Huang ${ }^{1}$, Li Zheng ${ }^{1,2}$, Jinmin Zhao ${ }^{1,2,3}$ and Xingdong 7 hai \\ Neuro-osteological interactions have an important role in the regulation of bone metabolism a d regen. tion. Neuropeptides \\ combined with porous biphasic calcium phosphates (BCP) using protein adsorption may cr itr. te to the acceleration of bone \\ formation. In the present study, we investigated the effect of BCP combined with nerve growth ta vr/NGF) on the growth of \\ osteoblasts in vitro and the combinational therapeutic effect on the repair of calvarial at. ts in vivo. NGF was separated and \\ purified from Chinese cobra venom using a simplified three-step chromatography nic od a combined with NGF exerted a \\ potent effect on osteoblast differentiation, as evidenced by enhanced cell proliferation, creased ALP activity and the up- \\ regulated expression of osteogenesis-related genes and proteins. Further, comi ational $t$, erapy with BCP and NGF improved \\ calvarial regeneration, which was superior to treatment with therapy alone, as obst using imageological and morphological \\ examination and histological and immunohistochemical staining. The results cor irmed the effect of neuro-osteological \\ interactions through combinatorial treatment with NGF and BCP to p-nte ostec senesis and bone formation, which may
} provide an effective and economical strategy for clinical applicati

Experimental \& Molecular Medicine (2017) 49, e312; doi:10.103 16.173; published online 7 April 2017

\section{INTRODUCTION}

Calcium phosphate (Ca-P) ceramics have been wi bone substitutes in the restoration of calvaris defec and lateral, vertical bone augmentation models. ${ }^{4}$ Among various Ca-P ceramics, porous biphasic calcium 1 osphate ceramics (BCP) have attracted much attention in the struction of large and complex bone defects be of their excellent osteoconduction and proper deoradation. ${ }^{-\infty}$, Aowever, a rather long duration of the bon $\mathrm{CO}_{1}$ olidat on phase is typically required after therapy using complications and inc nvenieno are clinics. It is important to identify an effectiv mo do accelerate bone formation and reduce the dur $n$ non of thi Merapy.

It has be pi pposed that bone metabolism is regulated by neuro-osteo ical interactions. ${ }^{8-10}$ Multiple studies have reveal $d t$ t a amber of neuropeptides secreted by the skeleta ers exert a robust effect on osseous formation and bone resorption. ${ }^{10,11}$ Among the numerous neurotrophins, nerve growth factor (NGF) is frequently used in bone defect therapies. ${ }^{12-14}$ NGF exists in many animals and can be extracted from submaxillary salivary glands, bovine seminal plasma, snake venom and so on ${ }^{15-21}$ Among these sources, snake venom-derived NGF exhibits better bioactivity and stability than the venom from other sources. ${ }^{15-17}$ NGF stimulates bone formation around the induced regenerating axons and improves bone fracture healing..$^{22,23}$ The injection of NGF is a useful method to stimulate bone formation ${ }^{14,24,25}$ NGF can also be delivered using various scaffolds, including agarose hydrogel, copolymers (PPy-NSE), poly-lactic-co-glycolic-acid (PLGA) and so on. ${ }^{26-32}$ However, most of the carriers for NGF are hydrogels or porous polymers that can hardly achieve the functional reconstruction of large-scale defects. A combination of NGF with Ca-P ceramics, such as BCP, may hold promise in the therapy of extensively damaged bone.

\footnotetext{
${ }^{1}$ Guangxi Engineering Center in Biomedical Materials for Tissue and Organ Regeneration, The First Affiliated Hospital of Guangxi Medical University, Nanning, People's Republic of China; ${ }^{2}$ Guangxi Collaborative Innovation Center for Biomedicine, The First Affiliated Hospital of Guangxi Medical University, Nanning, People's Republic of China; ${ }^{3}$ Guangxi Key Laboratory of Regenerative Medicine, The First Affiliated Hospital of Guangxi Medical University, Nanning, People's Republic of China; ${ }^{4}$ The Medical and Scientific Research Center, Guangxi Medical University, Nanning, People's Republic of China and ${ }^{5}$ National Engineering Research Center for Biomaterials, Sichuan University, Chengdu, People's Republic of China

6These authors contributed equally to this work.

Correspondence: Professor L Zheng and Professor J Zhao, Guangxi Engineering Center in Biomedical Materials for Tissue and Organ Regeneration, The First Affiliated Hospital of Guangxi Medical University, 6\# Shuangyong Road, Nanning 530021, Guangxi, China.
}

E-mail: zhengli224@163.com or zhaojinmin@126.com

Received 7 September 2016; revised 9 November 2016; accepted 14 November 2016 
A composite system comprising inorganic phases and organic substrates is difficult to prepare. Although proteins can be immobilized onto the surfaces of ceramics by chemical modifications to form covalent bonds, protein properties, including the structure, conformation or aggregation, may be altered. Alternatively, ceramics can be used to absorb proteins. Emerging evidence indicates that $\mathrm{Ca}-\mathrm{P}$ ceramics have protein adsorption capacity, which may underlie the osteoinduction observed after implantation in vivo. In addition, Ca-P ceramics have also been exploited for protein separation and protein anchorage. ${ }^{33}$ In particular, BCP is promising in the adsorption of proteins, as these molecules easily form microporous structures and exhibit an affinity for proteins. ${ }^{34-36}$ Proteins, such as fibronectin, bone sialoprotein and transforming growth factor, are selectively adsorbed onto the surface of Ca-P ceramics. ${ }^{35,37,38}$ This feature may be useful for combinational therapy using BCP and neuropeptides, such as NGF, for bone defects.

In the present study, we investigated the role of BCP combined with NGF from Guangxi cobra venom on the growth of osteoblasts in vitro and the repair of calvarial defects in vivo. To separate and purify the Chinese cobra venom, we improved upon a simplified three-step chromatography method described in a previous study. ${ }^{39,40}$ NGF was retained by BCP using protein absorption. Thus, the aim of the present study was to employ neuro-osteological interactions to short the duration of the bone consolidation phase.

\section{MATERIALS AND METHODS}

\section{Purification of NGF}

As shown in Figure 1A, crude Guangxi cobra veno h $h$ sequentally separated on Sephadex G-50, CM Sepharos PF an superdex 75 PG chromatography columns. Briefly $2 \mathrm{~g}$ lyophilized cobra venom powder was thoroughly dissolved it $10 \mathrm{ml}$ of $1 \%$ acetic acid
(HAC, Sigma-Aldrich, St Louis, MO, USA) at $4{ }^{\circ} \mathrm{C}$. After centrifugation at 12,000 r.p.m. for $10 \mathrm{~min}$ at $4{ }^{\circ} \mathrm{C}$, the supernatant was collected, passed through Sephadex G-50 (GE Healthcare Bio-Sciences China Ltd, Beijing, China) at the rate of $1 \mathrm{ml} \mathrm{min}^{-1}$, and eluted with $1 \%$ acetic acid. A 10-ml fraction containing NGF activity was obtained and loaded onto CM Sepharose FF (GE Healthcare Bio-Sciences China) after overnight dialysis and gradient elution with $0.02 \mathrm{~mol}^{-1}$ sodium acetate-acetic acid (NaAC-HAC, $\mathrm{pH}$ 5.8, s.ma-Aldrich) ranging from 0 to $1 \mathrm{moll}^{-1}$ sodium chloride ( $\mathrm{NaCl}$ Sigr) a-Aldrich). The fraction with NGF activity was collected and slow epara $\mathrm{d}$ on Superdex $75 \mathrm{pg}$ (GE Healthcare Bio-Sciences China) at $0 . \mathrm{min}^{-1}$. After elution with $1 \% \mathrm{HAC}$, the fraction th NGl activity was collected, dialyzed for desalination ma lyop ized. Finally, the purified NGF was dissolved in norr al saline at concentration of $0.1 \mathrm{mg} \mathrm{ml}^{-1}$ as a stock solution and red at $-20^{\circ} \mathrm{C}$.

\section{Molecular weight as of NGF}

Lyophilized powder was cor etely dissolved in $1 \% \mathrm{HAC}$, and the molecular mass $m$ determ, sed using sodium dodecyl sulfate polyacrylamid rel lactrophoresis (SDS-PAGE, Sigma-Aldrich) SDS. Subsequent, the gel was fixed using $12 \%$ trifluoroacetic acid (Sigma- ${ }^{3}$ rich) and rained with Coomassie Blue R-250 (Shanghai Solarbio Scier Technology, Shanghai, China).

\section{B tivity assay of NGF}

PC1. cells (purchased from Institute of Cell Biology, Chinese demy of Science, Shanghai, China) were cultured in alpha-modifhed Eagle's medium ( $\alpha$-MEM, Gibco BRL, Gaithersburg, MD, USA) containing $10 \%(\mathrm{v} / \mathrm{v})$ fetal bovine serum (FBS, Gibco BRL) and $1 \%$ (v/v) antibiotics (penicillin $100 \mathrm{U} \mathrm{ml}^{-1}$, streptomycin $100 \mathrm{U} \mathrm{ml}^{-1}$, Beijing Solarbio Science and Technology, Beijing, China) with or without $2 \mu \mathrm{g} \mathrm{ml}^{-1} \mathrm{NGF}$. NGF bioactivity was verified based on morphological changes of PC12 cells after $24 \mathrm{~h}$.

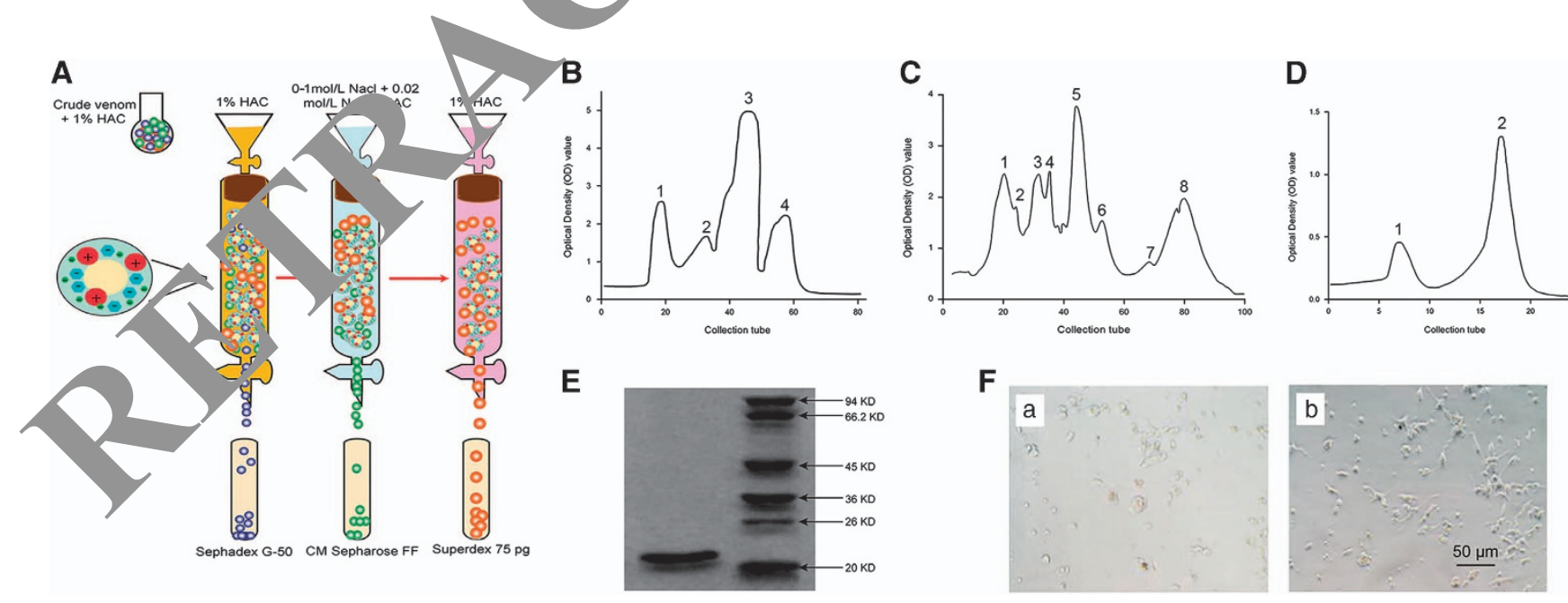

Figure 1 Purification and bioactivity assay of nerve growth factor (NGF) from crude Guangxi cobra venom. (A) Purification of NGF. (B) Chromatogram of crude venom on Sephadex G-50. Symbols 1, 2, 3 and 4 separately denote the isolated chromatographic peaks. (C) Chromatogram of crude venom on a CM Sepharose FF column. Symbols 1, 2, 3, 4, 5, 6, 7 and 8 separately denote the isolated chromatographic peaks. (D) Chromatogram of the NGF fraction on a Superdex 75 PG column. Symbols 1 and 2 separately denote the isolated chromatographic peaks. (E) Electropherogram of NGF and model proteins on SDS-PAGE. (F (a,b)) PC12 cells cultured without (a) and with (b) $2 \mu \mathrm{g} \mathrm{ml}^{-1} \mathrm{NGF}$ for $24 \mathrm{~h}$ (Scale bar $=50 \mu \mathrm{m}$ ). 


\section{In vitro experiment}

Primary osteoblasts were harvested from the bilateral parietal bone of newborn Sprague-Dawley (SD) rats (Animal Resources Center of Guangxi Medical University, Nanning, Guangxi, China) using enzymatic digestion. After being stripped clearly with sterile gauze and digested with $0.25 \%$ trypsin-ethylene diamine tetraacetic acid (EDTA) (Beijing Solarbio Science and Technology), the bilateral parietal bones were cut into pieces and subsequently digested with $1 \mathrm{mg} \mathrm{ml}^{-1}$ collagenase type I (Gibco BRL) for $3 \mathrm{~h}$. After centrifugation, the isolated cells were resuspended and subsequently cultured at $37^{\circ} \mathrm{C}$ in a $5 \% \mathrm{CO}_{2}$ incubator (Thermo Scientific TM Forma Series II Water-Jacketed, Santa Ana, CA, USA), and the medium was changed every other day.

\section{Preliminary screening and cytotoxicity assay}

Preliminary screening and cytotoxicity analysis were assessed using the 3-(4,5-dimethylthiazol-2-yl)-2,5-diphenyltetrazolium bromide (MTT, Sigma-Aldrich) method. For preliminary screening, the cells were cultured with NGF ranging from 0.625 to $250 \mu \mathrm{g} \mathrm{ml}^{-1}$ in monolayer or BCP-based three-dimensional (3D) cultures. BCP $(\mathrm{HA} / \beta-\mathrm{TCP}=60 / 40$, diameter $=12 \mathrm{~mm}$, thickness $=2 \mathrm{~mm}$, porosity $=$ $75 \% \pm 5 \%$ ) blocks were purchased from National Engineering Research Center in Biomaterials of Sichuan University of China. After preliminary screening, optimal concentrations of NGF were selected for further cytotoxicity analysis using an MTT assay in both 2D and 3D culture systems after 2, 5 and 8 days. Briefly, MTT was added to each well at a final concentration of $0.5 \mathrm{mg} \mathrm{ml}^{-1}$. After incubation for $4 \mathrm{~h}, 1 \mathrm{ml}$ dimethyl sulfoxide (DMSO, Sigma-Aldrich) was added for formazan-crystal solubilization. The absorbance was measured at $570 \mathrm{~nm}$ using a microplate reader (Thermo Scientific Multi kan GO Microplate Spectrophotometer, Helsinki, Finland). Prelim screening and cytotoxicity assays were performed in triplicate.

\section{Cell viability assay}

Cell viability was assessed using fluorescein d acetate (FDA Life Technologies (AB \& Invitrogen), Carlsbad, ( I, USA)-propidium iodide (PI, Life Technologies (AB \& Invitrogen tainin?. The cells were incubated with $5 \mu \mathrm{g} \mathrm{ml}^{-1} \mathrm{FDA}$ and ${ }^{-1 \mathrm{~g} \mathrm{ml}}+\mathrm{m}$ the dark for 5 min. The images were captured using a canning confocal microscope (Nikon A1, Tokyo, Jamn).

\section{Cell actin cytoskeleton deto}

Actin filaments were st ned to ob ve the cell's actin cytoskeleton. After culture for 2, 5 hd ays, thecells were washed with PBS, fixed with $4 \%$ paraform ' ldehyde ma-Aldrich), permeabilized with $0.5 \%$ Triton-X (Gib o RRL) and moubated with rhodamine phalloidin
(Cytoskeleton, Denver, CO, USA) and Hoechst 33258 (Sigma-Aldrich) in the dark. Cell cytoskeleton organization was observed using a laser scanning confocal microscope.

\section{Alkaline phosphatase activity assay and ALP staining}

Alkaline phosphatase (ALP) activity assay and ALP staining were performed using an ALP detection reagent and an ALP staining kit (both purchased from Nanjing Jiancheng Bioengineering Desearch Institute, Nanjing, China), respectively, according to th manufacturer's instructions. Culture medium was collected for the Dativi y assay, and the cells were harvested for ALP staining after 5and 8 days. The absorbance was measured at $520 \mathrm{n}$, sing a mic oplate reader. All reactions were performed in tri lical 'mage of ALP staining were acquired using an inverted phase cont microscope (Olympus, Tokyo, Japan).

\section{Real-time polymerase chain rea $n$}

Expression of bone morpho netic pro $\% 22$ (BMP2), runt-related transcription factor $2\left(R Y N \lambda_{\text {a }}\right.$ alkaline phosphatase $(A L P)$, bone sialoprotein $(B S P)$, ostencalcin (c $y$ ) and alpha-1 type I collagen (COL1A1) was deter ed u hg RT-PtR. On days 2, 5 and 8, total RNA was extracted using B action kit (Beijing ComWin Biotech, Beijing, China) accordh to the manufacturer's instructions. An equal amount of (300 $\mathrm{g})$ was used as a template for reverse transcription into A using a reverse transcription kit (Fermentas Company, Pitts burgh, PA, USA), and the cDNA was subsequently ar using a SYBR-Green mix (Roche, Berlin, Germany) and a al-tin fluorescence quantitative instrument (Realplex 4, Eppendorf o orat on, Hamburg, Germany). The primers used for PCR are pres d in Table 1. Gene expression was analyzed using the $2^{-\Delta \Delta \mathrm{CT}}$ $\mathrm{m}$ thod with $\beta$-actin as a control. All samples were assessed in trplicate.

\section{Calcium nodule detection}

Calcium nodule detection was performed using Alizarin red staining. After 8 days, the cells were fixed in ice-cold $70 \%(\mathrm{v} / \mathrm{v})$ ethanol for $1 \mathrm{~h}$, rinsed twice with deionized water and stained with an Alizarin Red S (Sigma-Aldrich) solution ( $40 \mathrm{~mm}, \mathrm{pH} 4.2$ ) for $10 \mathrm{~min}$ at room temperature. Excess dye was gently washed away with running water. Calcification deposits were typically stained red and photographed using an inverted phase contrast microscope.

Protein adsorption study and surface characteristics of BCP The protein adsorption capacity of BCP was assayed using the BCA protein assay kit (BOSTER, WuHan, China) and calculated according to the calibrated curve using BSA as a standard at 3, 24, 48, 72, 96,

\begin{tabular}{|c|c|c|}
\hline$\beta$-actin & 5'-CCCATCTATGAGGGTTACGC-3' & 5'-TTTAATGTCACGCACGATTTC-3' \\
\hline BMP2 & 5'-TGCTCAGCTTCCATCACGAA-3' & 5'-AATTTTGAGCTGGCTGTGGC-3' \\
\hline$R \cup N X 2$ & 5'-CCAAGTGGCCAGGTTCAACG-3' & 5'-GGGATGAGGAATGCGCCCTA-3' \\
\hline ALP & 5'-GTTACAAGGTGGTGGACGGT-3' & 5'-ACAGTGGTCAAGGTTGGCTC-3' \\
\hline COLIA1 & 5'-CATGAGCCGAAGCTAACCC-3' & 5'-CTCCTATGACTTCTGCGTCTGG-3' \\
\hline
\end{tabular}

Abbreviations: $A L P$, alkaline phosphatase; BMP2, bone morphogenetic protein-2; BSP, bone sialoprotein; $\beta$-actin, beta-actin as the normalization control; COL1A1, alpha-1 type I collagen; OCN, osteocalcin; RUNX2, runt-related transcription factor 2. 
120, 144 and $168 \mathrm{~h}$. All samples were assessed in triplicate. The surface characteristics of BCP were observed using a scanning electron microscope (SEM, SU8020, HITACHI, Tokyo, Japan).

\section{Scanning electron microscope detection}

The surface of BCP before and after absorption with NGF was observed using an s.e.m. After 2, 5 and 8 days, the cells on the 3D matrix were also observed using an s.e.m. Briefly, the samples were washed with PBS ( $\mathrm{pH} 7.4$ ) and fixed in $4 \%$ paraformaldehyde for $15 \mathrm{~min}$. Subsequently, the fixed samples were gradually dehydrated, incubated in iso-amyl acetate for $5 \mathrm{~min}$ and dried. After the substrates were sputter coated with gold, the images were obtained using SEM (VEGA3, TESCAN Company, Brno, Czech Republic).

\section{In vivo experiment}

Surgical procedure. Sixty male SD rats weighing $300 \pm 20 \mathrm{~g}$ were obtained from the Animal Resources Center of Guangxi Medical University (Nanning, Guangxi, China). All experiments were performed in accordance with the relevant guidelines and regulations approved by the Animal Care \& Welfare Committee of Guangxi Medical University (Protocol Number: 20141003 A). After randomly dividing the animals into BCP and BCP-NGF groups, with 30 rats per group, the rats were anesthetized with a $2 \%$ pentobarbital sodium solution via intraperitoneal injection. Critical-size defects $(5 \mathrm{~mm}$ in diameter) were created using a dental drill on the right parietal bone. The defects were implanted with BCP pre-immersed in 0 or $2.5 \mu \mathrm{g} \mathrm{ml}^{-1} \mathrm{NGF}$ solution for 7 days. After the surgical experimen the rats in both groups were intraperitoneally injected with dextrose and normal saline, whereas those in the BCP-NGF group wer injected with NGF solution at a dose of $2.5 \mu \mathrm{g} \mathrm{g}^{-1}$ body weight via $\tau$ once a week for 4,8 and 12 weeks.

Computed tomography imaging analysis, microcompute. amography analysis and morphological observation. Th healing pi -ess was observed at 4, 8 and 12 weeks after impla tation using cone beam computed tomography (CBCT, Sirona, Ga os, Sierhens Aktiengesellschaft, Munich, Germany). After tomogr acquisition, 3D reconstructive images of the samples m onerated from $2 \mathrm{D}$ slices using machine built-in software. A+ar banging, the rats were sacrificed, and the entire defect e skull were harvested. Morphological observation was pert vestigate immunoreaction and new bone formation at the do site. At week 12, the samples were fixed in formal h, nned and analyzed using microcomputed tomography ( icro-CT, anghai Showbio Biotech, Shanghai, China). Histologion a sis ond immunohistochemical staining. After rinsing with coline, ng ith paraformaldehyde, decalcifying with formic ac an embeg $\mu$ ng in paraffin, the 5 - $\mu$ m-thick sections were cut th. nter of the calvarial defects. For histological analysis, the sectio were subjected to hematoxylin and eosin (HE) staining.

For inmunohistochemical staining, the sections were heated with citrate buffer for antigen retrieval, blocked with normal blocking serum, and subsequently incubated with mouse anti-osteocalcin (OCN, 1:1000, Santa Cruz, USA) or mouse anti-bone morphogenetic protein-2 (BMP2, 1:1000). After washing three times with PBS, the sections were incubated with goat anti-mouse antibody (1:1000, Santa Cruz, CA, USA), stained with substrate-chromogen solution $3,3^{\prime}$-diaminobenzidine tetrahydrochloride (DAB), and observed using an inverted phase contrast microscope.

\section{Statistical analysis}

The values were expressed as the means \pm s.d. and compared using a one-way analysis of variance (ANOVA). The least significance difference test (LSD-t) was performed for further evaluation of the data. SPSS software (version 16.0, SPSS, Chicago, IL, USA) was used, and $P<0.05$ was considered a significant difference.

\section{RESULTS}

\section{Purification and bioassay of NGF}

NGF was extracted from Chinese cobra ven afte gel filtration and chromatography through Sephadex 50, CM Sepharose FF and Superdex 75 PG. Th fractions of peak 2 (Figure 1B), peak 5 (Figure 1C) and p 2 (Figure 1D) were determined based on NGF bioactivity) and sequentially collected. The purified NGF yas lycoprotein with molecular weight of $22.3 \mathrm{kDa}$ (Figure A s way with pheochromocytoma PC12 cells revered the omotion of fiber outgrowth, which is typical of NG tivity (rigure $1 \mathrm{~F}(\mathrm{~b})$ ).

\section{Effects of NGP OA nonolayer-cultured osteoblasts}

Cytotoxicity shown in Figure 2A, preliminary screening revealo that NGF had no significant cytotoxicity at a conce ion raying from 0.625 to $15.625 \mu \mathrm{g} \mathrm{ml}^{-1}$, but it displayed ar a ibitive effect on osteoblasts at concentrations $>15.625 \mathrm{~g} \mathrm{ml}^{-1}$ after 3 days of culture. In the range of 1.25 2. $\mu \mathrm{g} \mathrm{ml}^{-1}$, NGF notably promoted cell growth. In the pre at study, concentrations of 2.5, 5 and $10 \mu \mathrm{g} \mathrm{ml}^{-1}$ were lected for further 2D investigation.

Further cytotoxicity analysis (Figure 2B) showed that NGF increased cell numbers in a time-dependent manner compared with the control. The cell number increased with time. Among the three concentrations, $5 \mu \mathrm{g} \mathrm{ml}^{-1} \mathrm{NGF}$ exhibited the strongest promoting effect on cell growth.

Cell viability assay and cell actin cytoskeleton detection. Cell viability was determined using FDA-PI staining (Figure 2C $(\mathrm{a}-\mathrm{d}))$, in which viable cells stained green and dead cells stained red. Consistent with the results of the cytotoxicity assay, more live cells were observed in the NGF-treated groups compared with the control at each time point, indicating that NGF exerted a positive effect on primary osteoblast survival. Among the experimental groups, the number of viable cells in the $5 \mu \mathrm{g} \mathrm{ml}^{-1} \mathrm{NGF}$ group was superior to that of other groups.

To assess the cytoskeleton reorganization of osteoblasts, actin filaments were detected through rhodamine phalloidin staining. As shown in Figure $2 \mathrm{C}(\mathrm{e}-\mathrm{h})$, more intensively polymerized actin was observed in the NGF-treated groups compared with the control, and these findings were confirmed using cytotoxicity and cell viability assays. Particularly, $5 \mu \mathrm{g} \mathrm{ml}^{-1}$ NGF exhibited the greatest induction of the actin cytoskeleton.

ALP activity assay and ALP staining. In all the groups, ALP increased in a time-dependent manner (Figure 2D). Comparatively, osteoblasts in the NGF-treated groups exhibited significantly higher ALP activity than control, which was 
A
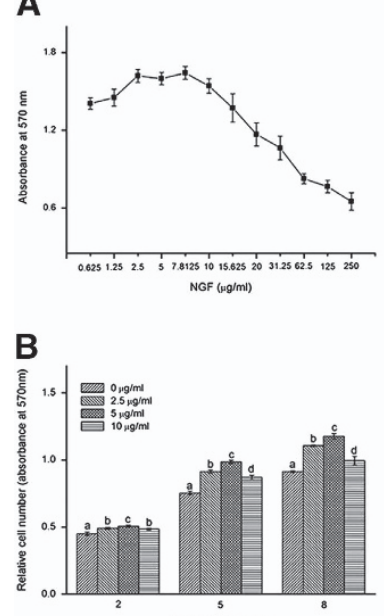

D

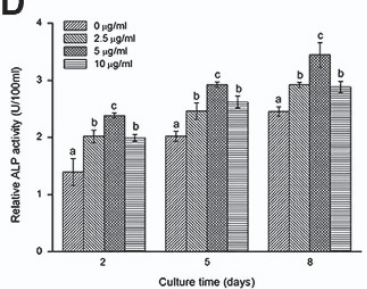

C
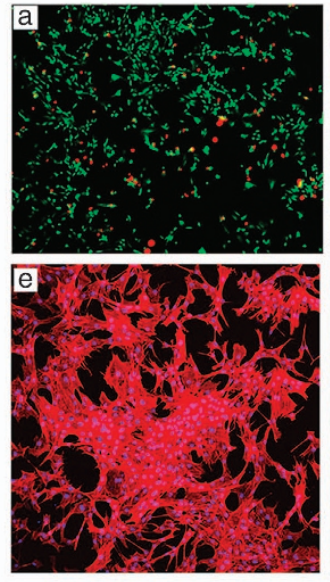

E

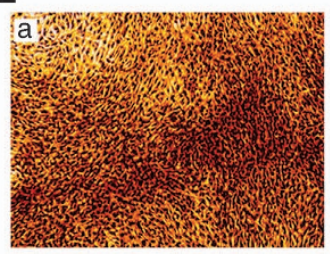

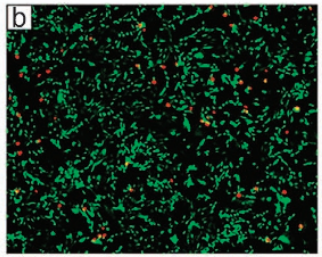
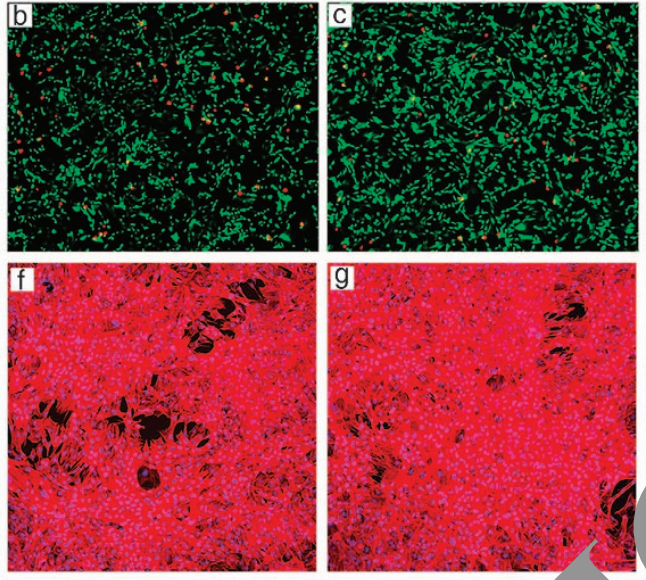
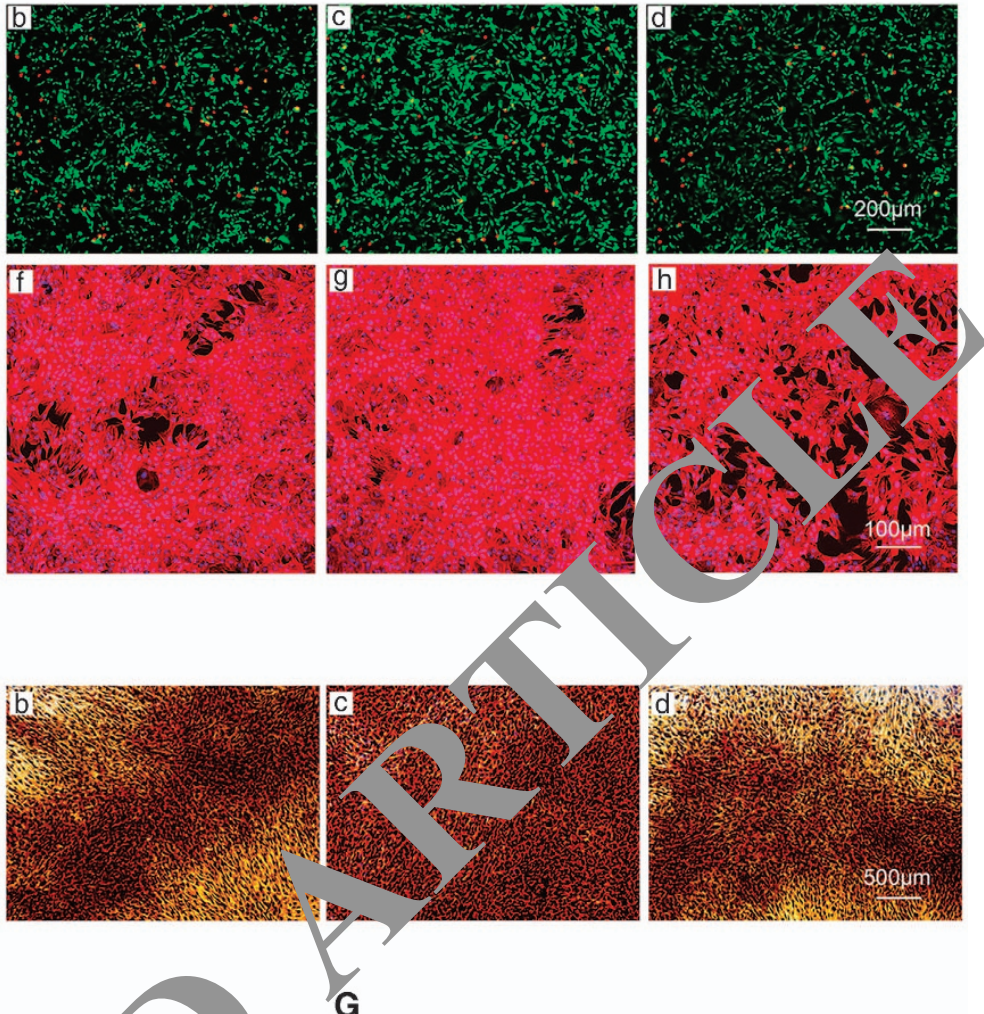

G
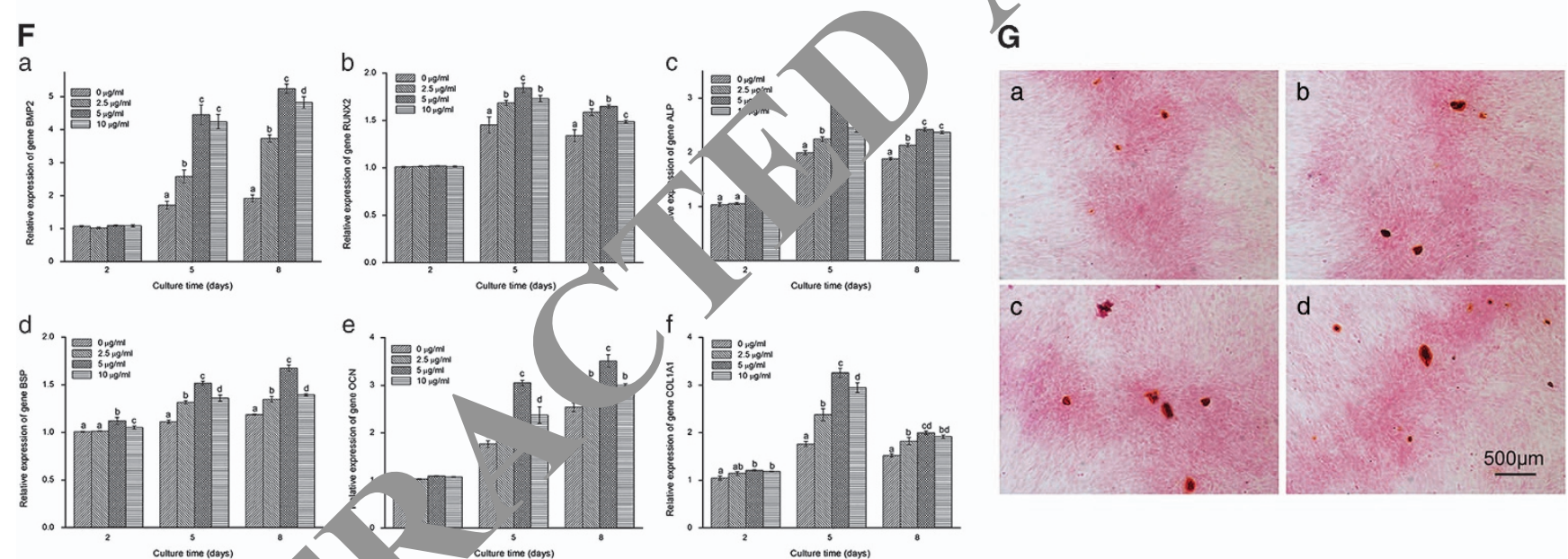

Figure 2 Concentration reening, cotoxicity assay, FDA-PI staining, rhodamine phalloidin-Hoechst 33258 staining, alkaline phosphatase (ALP) activity assay, AL, taining, osteogenic-specific gene expression and Alizarin red staining of monolayer-cultured osteoblasts. (A) Screening of Merve grow Vactor (NGF) using various concentrations (0.625, 1.25, 2.5, 5, 7.8125, 10, 15.625, 20, 31.25, 62.5, 125 and $250 \times \mathrm{m}^{-1}$ ) on 20 cultured osteoblasts using the MTT method after 3 days of treatment $(n=3)$. (B) Cytotoxicity assay with NGF at $0,2.5$, nd 1 $\mu \mathrm{g} \mathrm{ml}^{-1}$ on days 2, 5 and $8(n=9)$. (C (a-d)) FDA-PI staining of osteoblasts treated with NGF at $0,2.5,5$ and $10 \mu \mathrm{m} / \mathrm{ys}$ of treatment (Scale bar $=200 \mu \mathrm{m})$. (C (e-h)) Rhodamine phalloidin-Hoechst 33258 staining of a monolayer cultu treat d with $0,2.5,5$ and $10 \mu \mathrm{g} \mathrm{ml}^{-1} \mathrm{NGF}$ after 8 days (Scale bar $=100 \mu \mathrm{m}$ ). (D) ALP activity assay of osteoblasts treated with 0 , 2.5, 5 L $10 \mu_{\mathrm{o}} \mathrm{ml}^{-1} \mathrm{NGF}$ on days 2, 5 and $8(n=9)$. (E (a-d)) ALP staining of osteoblasts treated with $0,2.5,5$ and $10 \mu \mathrm{ml} \mathrm{m}^{-1} \mathrm{NGF}$ after 8 da, 'Scale bar $=500 \mu \mathrm{m})$. ( $\mathbf{F}(\mathrm{a}-\mathrm{f}))$ Relative expression of bone morphogenetic protein-2 (BMP2, $\mathbf{F}(\mathrm{a}))$, runt-related transcription factor $2(R U N X 2, \mathbf{F}(\mathrm{b}))$, alkaline phosphatase $(A L P, \mathbf{F}(\mathrm{c}))$, bone sialoprotein $(B S P, \mathbf{F}(\mathrm{d}))$, osteocalcin $(O C N, \mathbf{F}(\mathrm{e}))$ and alpha-1 type I collagen (COL1A1, F (f)) in osteoblasts treated with $0,2.5,5$ and $10 \mu g \mathrm{ml}^{-1} \mathrm{NGF}$ on days 2,5 and $8(n=3)$. (G (a-d)) Alizarin red staining of osteoblasts treated with $0,2.5,5$ and $10 \mu \mathrm{g} \mathrm{ml}-1$ NGF after 8 days (Scale bar $=500 \mu \mathrm{m}$ ). The values are presented as the means \pm standard deviation. Bars with different letters at the same time point are significantly different from each other at $P<0.05$, and bars with the same letter exhibit no significant difference.

further confirmed using ALP staining (Figure 2E). The highest ALP level in all the groups was observed with $5 \mu \mathrm{g} \mathrm{ml}^{-1}$ NGF.
Gene expression. The effect of NGF on osteoblasts was further investigated through an analysis of BMP2, RUNX2, ALP, BSP, $O C N$ and COL1A1 gene expression after 2, 5 and 8 days via 
RT-PCR assay. As shown in Figure 2F, BMP2, BSP and OCN expression was notably up-regulated by NGF at the three observation points. However, RUNX2, ALP and COL1A1 expression was remarkably up-regulated from day 2 to 5 and subsequently gradually down-regulated thereafter. These osteogenic-specific marker genes exhibited the greatest up-regulation after the administration of $5 \mu \mathrm{g} \mathrm{ml}^{-1} \mathrm{NGF}$.

Calcium nodules detection. Alizarin red staining was used to detect calcium nodules at day 8. Compared with the control, the formation of calcification deposits was more obvious after NGF treatment, particularly at $5 \mu \mathrm{g} \mathrm{ml}^{-1}$ (Figure 2G).

\section{Effects of BCP combined with NGF on osteoblasts}

Protein adsorption study and surface characteristics of BCPNGF. In the presence of BCP, the amount of NGF in the solution dramatically decreased after $3 \mathrm{~h}$, and gradually decreased thereafter, becoming stable after $120 \mathrm{~h}$ (Figure 3A (a)). In contrast, NGF concentration exhibited minimal variation in the control. This finding indicated that BCP adsorbed the majority of protein in the solution. An s.e.m. was used to investigate the surface of NGF-covered BCP after incubation for $168 \mathrm{~h}$ compared with BCP alone (Figure 3A (b)). As shown in Figure $3 \mathrm{~A}(\mathrm{c})$, protein deposition could be observed on the surface of BCP.

Concentration screening on BCP. As shown in Figure $3 \mathrm{~B}, 0.6$ to $2.5 \mu \mathrm{g} \mathrm{ml}^{-1} \mathrm{NGF}$ promoted cell growth, but the loses $>2.5 \mu \mathrm{g} \mathrm{ml}^{-1}$ displayed an inhibitive effect on osteo asts. In the present study, concentrations of $1.25,2.5$ and 5 were selected for further $3 \mathrm{D}$ investigation.

Cytotoxicity and cell viability assay. As shrwn in rure 3C, the cells proliferated in a time-depende it manner. Oompared with the control, the cell number inc ased makedly in the BCP-NGF group, verifying the promotin. ${ }^{\prime}$ ect of NGF on 3D culture. Live-dead cell staining wa od to determine the effect of NGF on cell viability. As showi ir 1 , are 3D, more viable cells (stained in green re pesent in the BCP-NGF group than the BCP a e (a,e,i)). In the BCP-NGF groups, ne nu er of live cells notably increased, and these cells a mately , ormed clusters and occupied a majority of the surfac of the matrices. Among the three doses, $2.5 \mu \mathrm{g} \mathrm{ml}$ NGF prom oted cell viability most prominently at all observ.

Cfl cy, keleto, organization. As shown in Figure 3E a section Vh hage construction revealed that actin polymerization reased with time in all groups. Comparatively, more intensive polymerized actin was distributed throughout the cytoplasm with more aggregation of the cells in the BCP-NGF groups compared with the control. Particularly, $2.5 \mu \mathrm{g} \mathrm{ml}^{-1}$ NGF exhibited the best performance.

Morphology of cells on BCP. Typical s.e.m. photographs of BCP combined with and without NGF are presented in Figure 4A. A large number of micro-pores $(10-100 \mu \mathrm{m}$ in diameter) distributed on the walls of macro-pores ranging from 100 to $400 \mu \mathrm{m}$ in diameter could be clearly observed. Cells spread with numerous filamentous extensions in BCP, indicating superior cell attachment to the BCP. More cells were observed in the BCP-NGF group (Figure 4A $(\mathrm{k})$ ) than in the control (Figure $4 \mathrm{~A}(\mathrm{a}, \mathrm{e}, \mathrm{i})$ ), which ultimately grew in clumps on the surface. This finding indicates the promotion effect of NGF absorbed on BCP, particularly at $2.5 \mu \mathrm{g} \mathrm{ml}^{-1}$.

ALP activity assay. As shown in Figure 4B cr ased ALP activity of osteoblasts on BCP combined wi NGF was observed from days 2 to 5 compare with th control, particularly at $2.5 \mathrm{\mu g} \mathrm{ml}^{-1}$. However A. activi $y$ obviously decreased from days 5 to 8 in all roups. Or ALP activity at $2.5 \mu \mathrm{g} \mathrm{ml}^{-1} \mathrm{NGF}$ was significant different from the control.

Gene expression. As shown Fig $4 \mathrm{C}(\mathrm{a}, \mathrm{d}, \mathrm{e})$, compared with the control, $B N P 2, B S$. and $O C N$ expression was up-regulated in $\mathrm{B} / \mathrm{P}$ mbined with NGF groups in a time-dependent manner, $\mathrm{P}$ iqularly at $2.5 \mu \mathrm{g} \mathrm{ml}^{-1}$. However, RUNX2, COI A1 a d ALP expression increased from day 2 to 5 but decrease 5 to 8 (Figure $4 \mathrm{C}(\mathrm{b}, \mathrm{c}, \mathrm{f})$ ) in the BCPNGF groups, anc. he levels were higher than the control at each tim

Therapeut $c$ effect of BCP combined with NGF on calvariala. $t$ model

Ima cological examination and gross morphological analysis. As wn in Figure 5A, the critical calvarial defects were implanted with BCP or BCP pre-immersed in NGF in group $\mathrm{BCP}$ or BCP-NGF respectively according to the model. One rat in the BCP group died at one week post-operation, which may reflect brain damage or infection. In addition, another rat in group BCP-NGF died during anesthesia, which may reflect excessive anesthetic. The remaining rats recovered well after operation and remained alive until the end of the study. After 4, 8 and 12 weeks of therapy, the samples were harvested for observation and analyses. As shown in Figure 5, no inflammation was observed in the engineered bone at weeks 4,8 and 12 . Imageological examination (Figures $5 \mathrm{~B}$ and $\mathrm{D}(\mathrm{b})$ ) and gross morphology observation (Figure 5C) showed the nearly complete repair of bone defects using combinational therapy. The new bone was remodeled and fused with the surrounding tissue after 12 weeks (Figure 5E), as evidenced by significant increases in parameters, including bone volume (BV, Figure $5 \mathrm{E}$ (b)) and the percentage of bone volume/total volume (BV/TV, Figure 5E (c)). Trabecular analyses were also significantly improved with NGF treatment, including an obvious increase in trabecular thickness (Tb.Th, Figure 5E (d)) and trabecular number (Tb.N, Figure 5E (e)), and a notable decrease in trabecular separation (Tb.Sp, Figure 5E (f)). However, the interface between the neo-bone and the original tissue remained obvious in the BCP-repaired defects, indicating less favorable bridging. In summary, all the data suggested that combinational therapy of BCP and NGF was superior to treatment with BCP alone. 
A
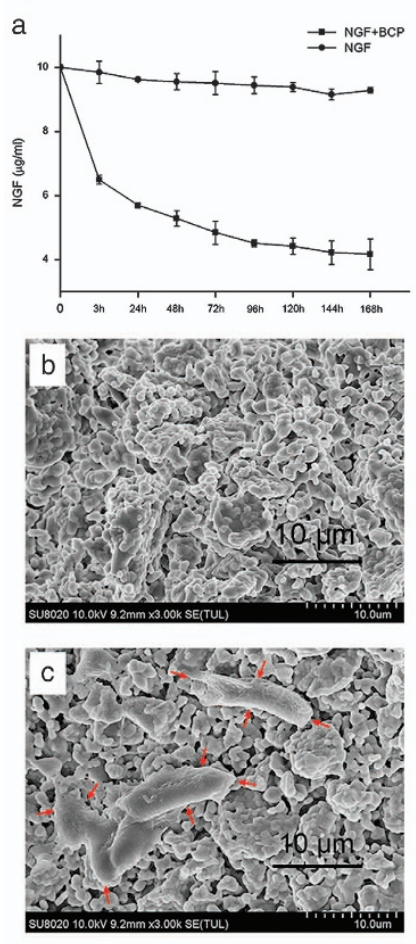

B

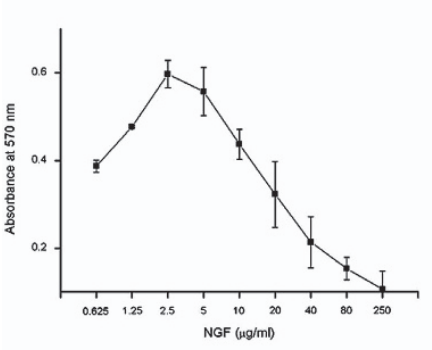

c

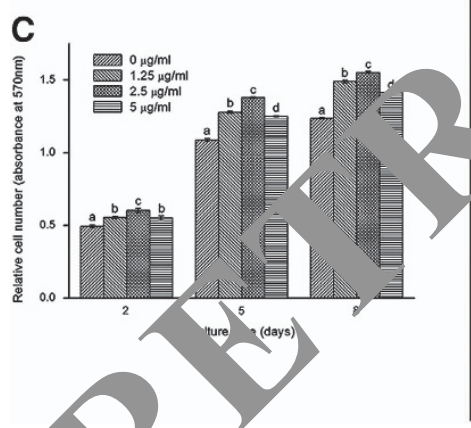

D
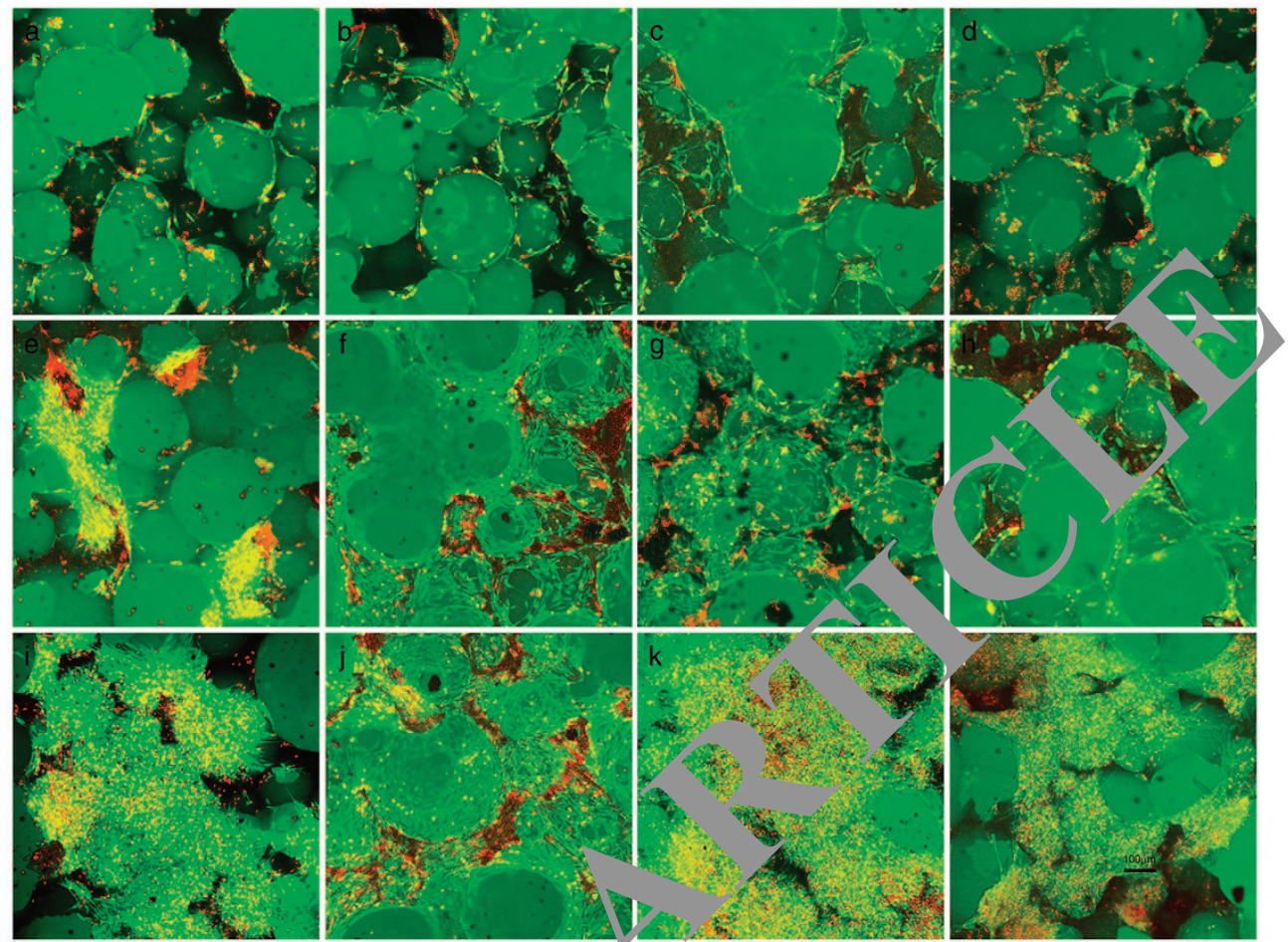

E
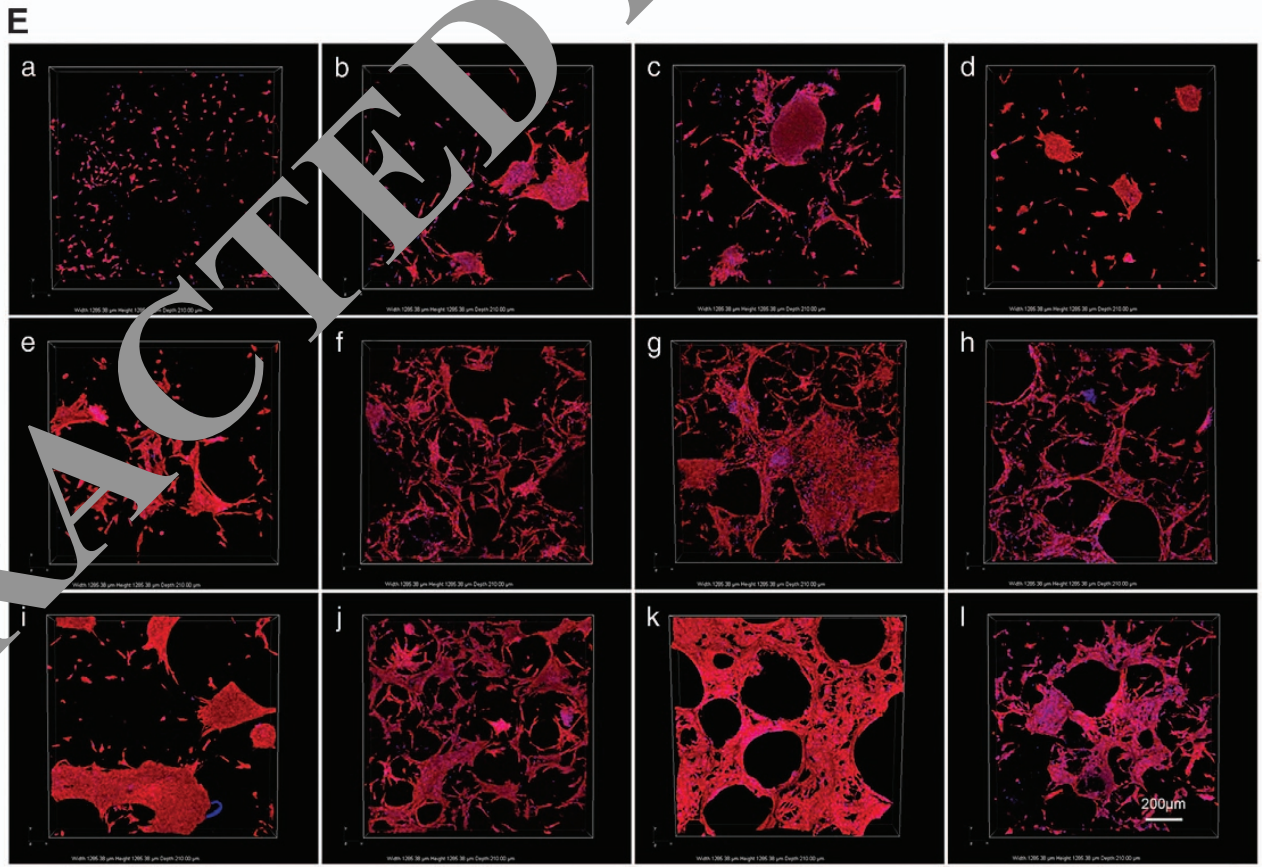

Figure - rotem adsorption study and surface characteristics of BCP, NGF concentration screening, cell viability and cell cytotoxicity assays, an il actin cytoskeleton detection on three-dimensional (3D) cultured osteoblasts. (A (a)) Protein adsorption isotherms of NGF without and with BCP after 3, 24, 48, 72, 96, 120, 144 and $168 \mathrm{~h}(n=3)$. (A (b,c)) Scanning electron microscope (s.e.m.) images of BCP combined with NGF at $0 \mu \mathrm{ml}^{-1}$ (b) and $10 \mu \mathrm{g} \mathrm{m} \mathrm{l}^{-1}$ (c) (Scale bar $=10 \mu \mathrm{m}$, protein deposits are indicated with red arrows). (b) Concentration screening of nerve growth factor (NGF) on three-dimensional (3D) culture using the 3-(4,5-dimethylthiazol-2-yl)-2,5diphenyltetrazolium bromide (MTT) method after 3 days of interference $(n=9)$. (C) Cytotoxicity assay of cells on BCP combined with different concentrations of $\operatorname{NGF}\left(0,1.25,2.5\right.$ and $\left.5 \mu \mathrm{g} \mathrm{ml}^{-1}\right)$ at days 2,5 and $8(n=9)$. The values are presented as the means $\pm \mathrm{s}$.d. Bars with different letters at the same time point are significantly different from each other at $P<0.05$, and bars with the same letter exhibit no significant difference. (D (a-I)) FDA-PI staining of osteoblasts on BCP treated with $0,1.25,2.5$ and $5 \mu \mathrm{gl} \mathrm{ml}^{-1} \mathrm{NGF}$ for 2,5 and 8 days (Scale bar $=100 \mu \mathrm{m})$. (E $(\mathrm{a}-\mathrm{I})$ ) 3D section views of rhodamine phalloidin-Hoechst 33258 staining on BCP combined with 0 , $1.25,2.5$ and $5 \mu \mathrm{g} \mathrm{ml}^{-1} \mathrm{NGF}$ treatment for 2,5 , and 8 days (Scale bar $=200 \mu \mathrm{m}$ ). 
A
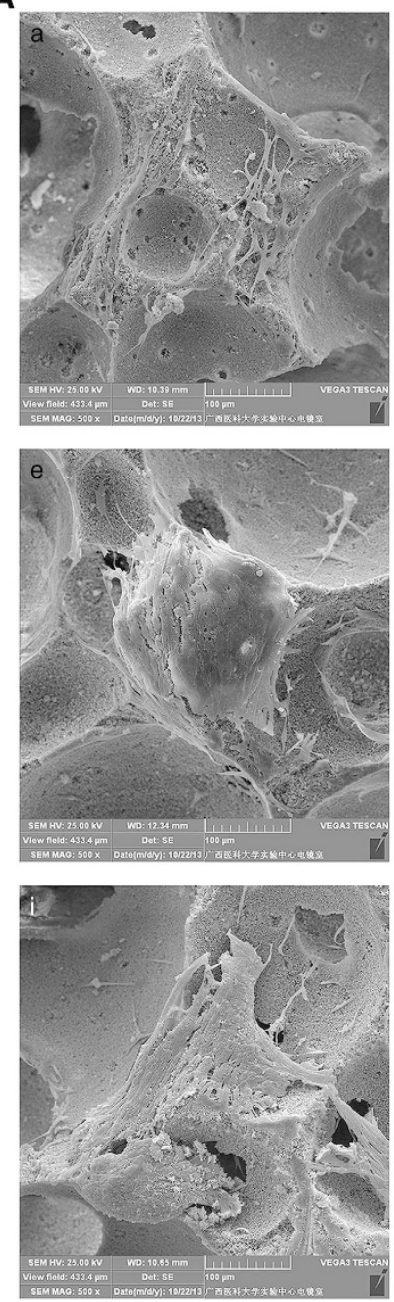

B

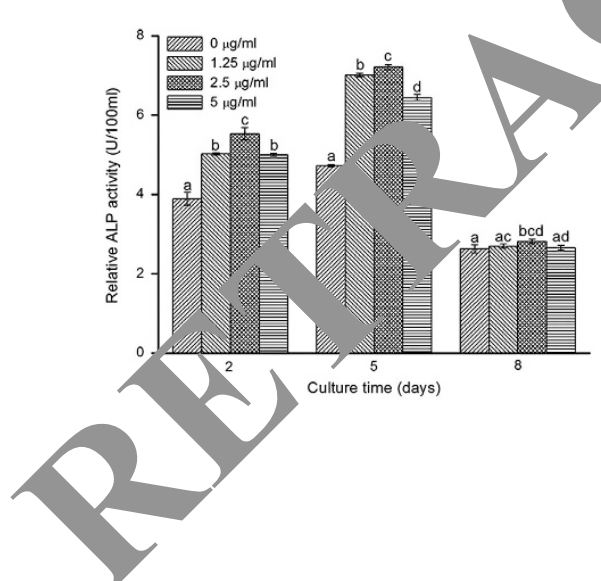

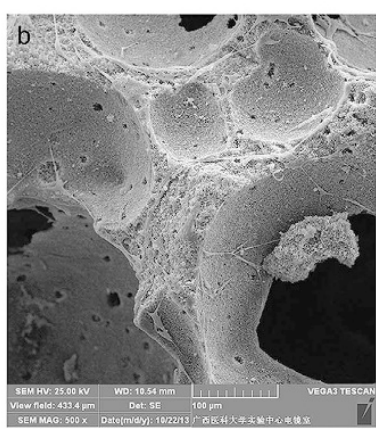
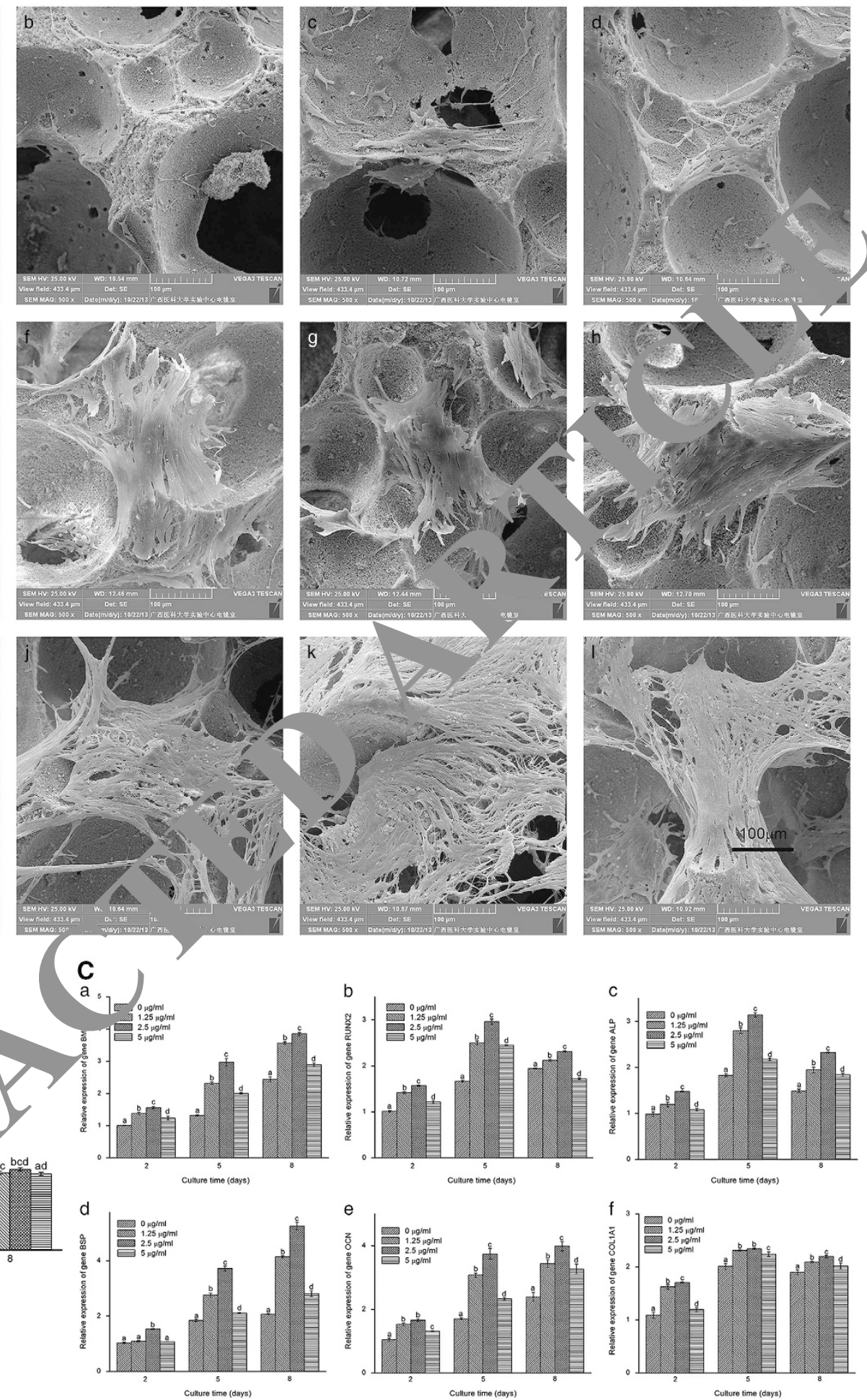

Figure 4 Scanning electron microscope (s.e.m.) detection, alkaline phosphatase (ALP) activity assay and gene expression analysis of threedimensional (3D) cultured osteoblasts. (A (a-I)) Typical s.e.m. photographs of osteoblasts on BCP combined with different concentrations of $\operatorname{NGF}\left(0,1.25,2.5\right.$ and $5 \mu \mathrm{g} \mathrm{ml}{ }^{-1}$ ) after 2,5 and 8 days (Scale bar $=100 \mu \mathrm{m}$ ). (B) Relative ALP activity (units/100 ml) in cells on BCP combined with $0,1.25,2.5$ and $5 \mu \mathrm{g} \mathrm{ml} \mathrm{I}^{-1} \mathrm{NGF}$ for 2,5 and 8 days $(n=9)$. (C (a-f)) Relative gene expression of bone morphogenetic protein-2 (BMP2, C (a)), runt-related transcription factor 2 (RUNX2, C (b)), alkaline phosphatase (ALP, C (c)), bone sialoprotein (BSP, C (d)), osteocalcin (OCN, C (e)) and alpha-1 type I collagen (COL1A1, C (f)) on BCP combined with $0,1.25,2.5$ and $5 \mu \mathrm{g} \mathrm{ml-1}$ of NGF on days 2,5 and $8(n=3)$. The data are presented as the means \pm standard deviation. Bars with different letters at the same time point are significantly different from each other at $P<0.05$, and bars with the same letter exhibit no significant difference. 
A

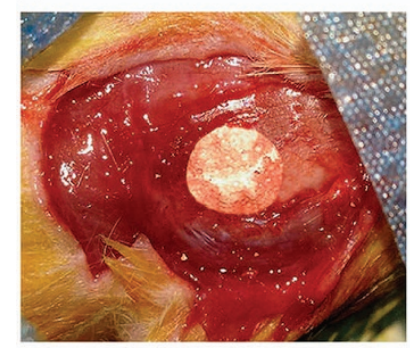

B
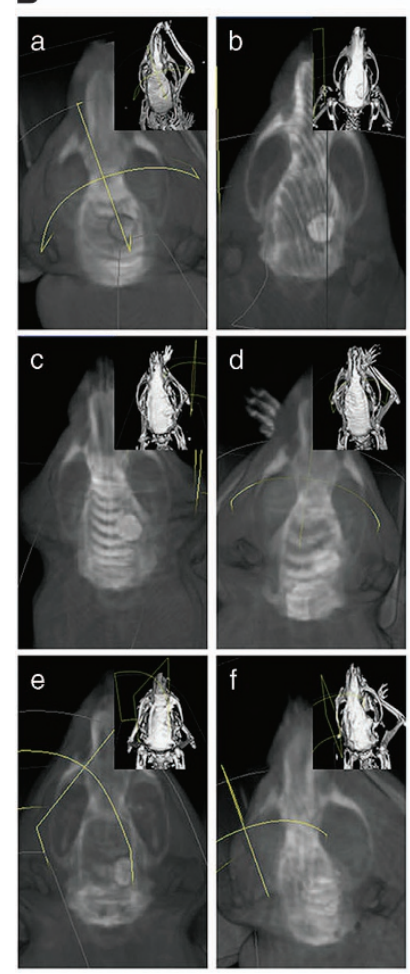

C
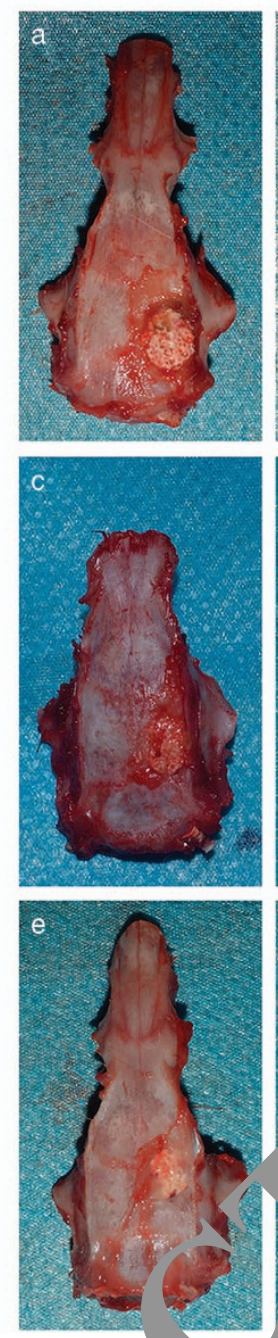
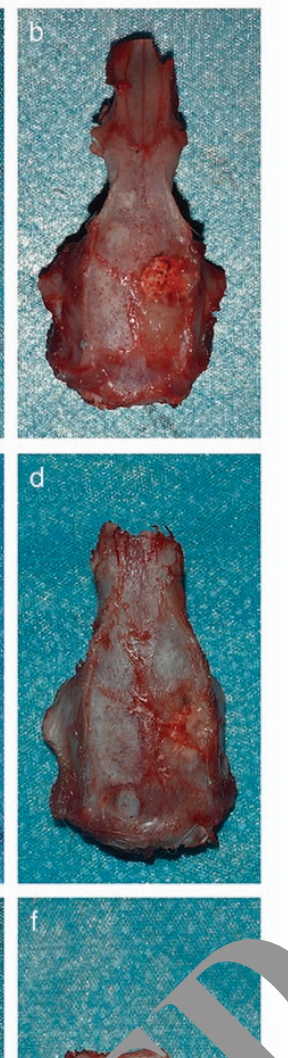

D
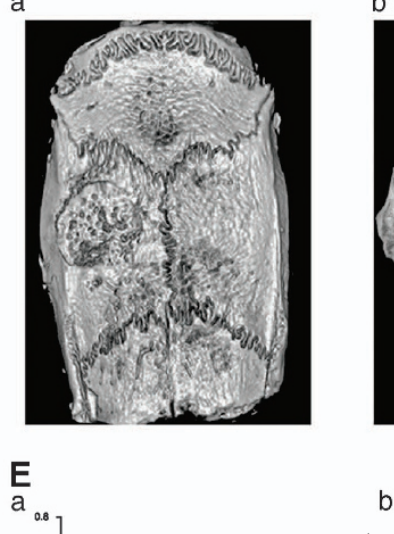

b
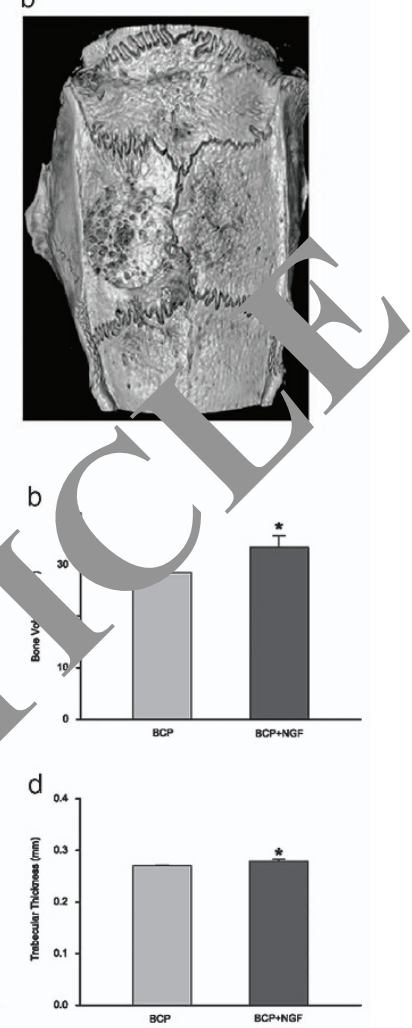

$f$

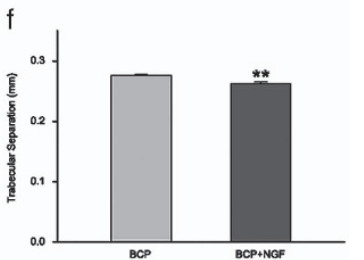

Figure 5 Imageological examination and gross im, nogical analysis of repaired calvarial tissue in the calvarial-defect model. (A) The critical calvarial-defect model with BCP med during the operation. (B) Cone beam CT scan of calvarial defects repaired by BCP combined without $(\mathbf{B}(a, c, e))$ or with NG ther,py $(\mathbf{B}(a, d, f))$ after 4,8 and 12 weeks. (c) Gross morphological observation of calvarial defects repaired by BCP combirec ithout (C, $(a, c, e)$ ) or with NGF therapy $(\mathbf{C}(b, d, f))$ after 4,8 and 12 weeks. (D) Representative threedimensional micro-CT recono tio a calvarial defects repaired by BCP combined without (D (a)) or with NGF therapy (D (b)) after 12 weeks. (E) Micro-CT quanth tion aata, including bone mineral density (BMD, E (a)), bone volume (BV, E (b)), bone volume/total volume (BV/TV, E (c)) becular $t_{i}$ kness (Tb.Th, E (d)), trabecular number (Tb.N, E (e)), and trabecular separation (Tb.Sp, $\mathbf{E}(\mathrm{f})$ ). $n=3$ samples per group. indi ss $P<0.05, * *$ indicates $P<0.01$. micro-CT, microcomputed tomography.

Histological. nminohistochemical analysis. HE staining (Figure 64) sho that new bone formed in the defect near the or gina one, nich became more uniform and compact as time $\mathrm{p}$ coun. Compared with bone repair by BCP alone, enhanced ne ingrowth with relatively more positive OCN (Figure 6B) and BMP2 (Figure 6C) staining was observed with combinational therapy. The boundary between the new bone and the original tissue was more compact in BCP and NGF therapy than with BCP alone.

\section{DISCUSSION}

BCP concentrates proteins on the surface, and this combination exerts synergistic effects on cell behavior. In the present study, we demonstrated that BCP combined with NGF significantly promoted the growth of osteoblasts and bone regeneration, and this system may be developed as a potential agent for skeletal reconstruction.

Regarding evidence for neuro-osteological interactions, NGF is pivotal not only in the maintenance and regeneration of nerves but also in the stimulation of the differentiation and inhibition of apoptosis of osteoblastic cells. ${ }^{14}$ The results of 2D culture in the present study showed that NGF greatly promoted osteoblast growth and differentiation, with more viable cells and higher ALP activity than the control (Figures $2 \mathrm{C}$ and E). After loading in BCP, the growth of osteoblasts and new bone formation were extensively increased, based on morphological, 


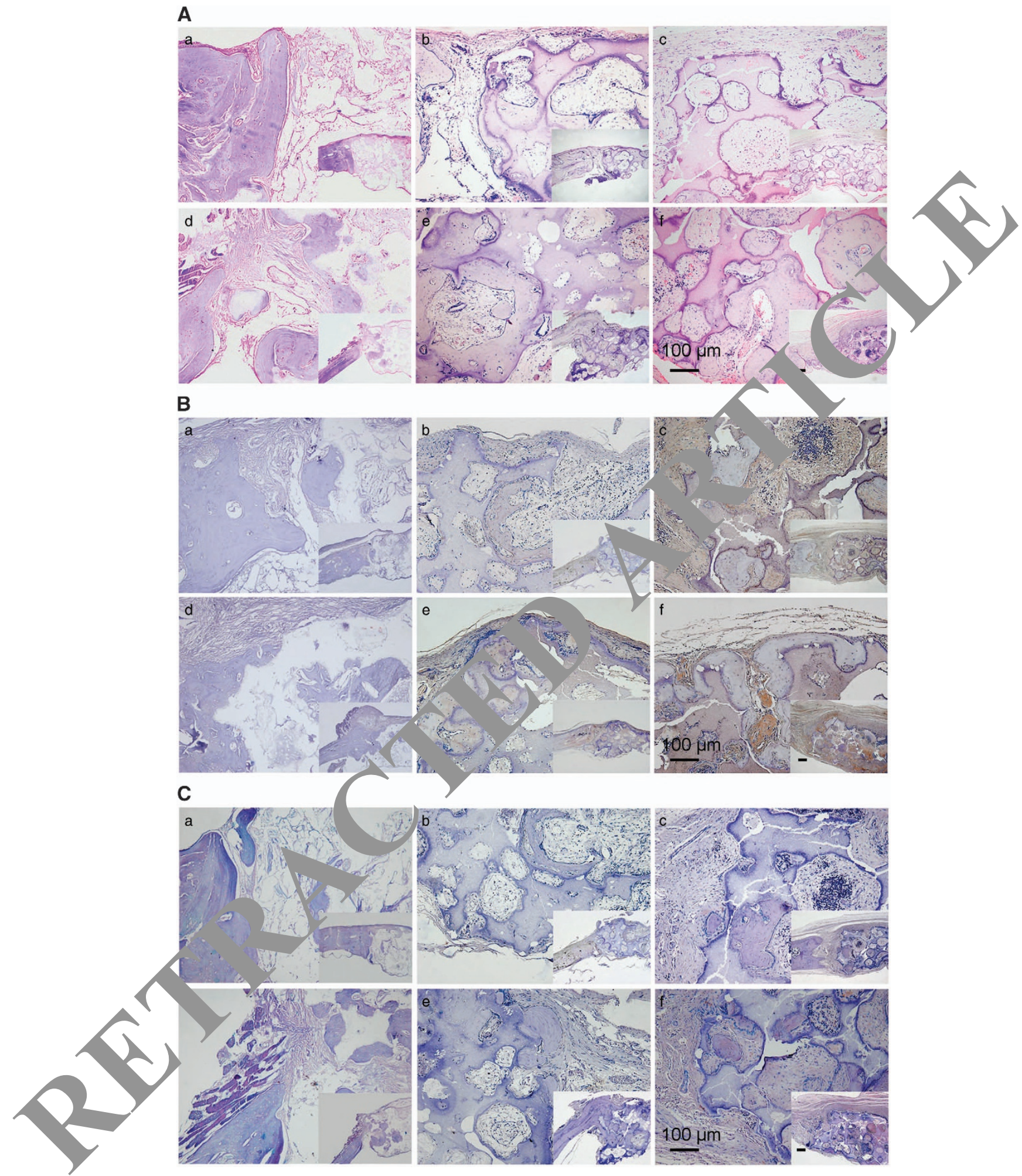

Figure 6 Hematoxylin-eosin (HE) staining and immunohistochemical staining on sections of repaired calvarial tissue. (A (a-f)) HE staining of repaired calvarial tissue from a calvarial-defect model implanted with BCP combined without or with NGF at weeks 4, 8 and 12 (Scale bar $=100 \mu \mathrm{m}$ in the large picture and Scale bar $=1000 \mu \mathrm{m}$ in the small picture). (B (a-f)) Osteocalcin (OCN) immunostaining of repaired calvarial tissue from the calvarial-defect model implanted with BCP combined without or with NGF at weeks 4, 8 and 12 (Scale $\mathrm{bar}=100 \mu \mathrm{m}$ in the large picture and Scale bar $=1000 \mu \mathrm{m}$ in the small picture). (C (a-f)) Bone morphogenetic protein-2 (BMP2) immunostaining of repaired calvarial tissue from a calvarial-defect model implanted with BCP combined with or without NGF at week 4,8 and 12 (Scale bar $=100 \mu \mathrm{m}$ in the large picture and Scale bar $=1000 \mu \mathrm{m}$ in the small picture). 
histological and PCR findings with increased markers for osteogenesis compared with either NGF or BCP alone. These findings indicate that BCP facilitates angiogenesis and osteoconduction, and NGF enables neurogenesis, both of which contribute to new bone formation.

An important feature of $\mathrm{Ca}-\mathrm{P}$ ceramics is protein adsorption, ${ }^{34,35}$ which favors the concentration of proteins in a natural manner. In the present study, NGF was immobilized on the surface of BCP, which was minimally released, even after 7 days of incubation. Interestingly, optimal NGF doses substantially differed between the monolayer and 3D cultures at $2.5-5 \mu \mathrm{g} \mathrm{ml}^{-1}$ and $1.25-2.5 \mu \mathrm{g} \mathrm{ml}^{-1}$, respectively. In particular, $5 \mu \mathrm{g} \mathrm{ml}^{-1} \mathrm{NGF}$ best supports cell growth in 2D culture, whereas $2.5 \mu \mathrm{g} \mathrm{ml}^{-1} \mathrm{NGF}$ was better than other doses in $3 \mathrm{D}$ culture, indicating that BCP selectively absorbed NGF in the culture medium, leading to the increased local concentration of NGF at the BCP surface.

Further exploration revealed that the combination of $\mathrm{BCP}$ and NGF promoted osteoblast differentiation through the regulation of the $B M P 2 / R u n x 2$ signaling pathway. This signaling has been identified as one of the major pathways for osteogenesis $^{41}$ and controls the downstream gene Runx2 through the $B M P$ signaling pathway. ${ }^{42-44}$ BMP2 exhibits a time-dependent increase after treatment with BCP and NGF (Figures 2F (a) and 4C (a)), indicating that osteoblast differentiation may be mediated by BMP2 signaling. As a downstream transcription factor, Runx2 increases at early stages and subsequently declines. The results were consh with those of a previous study ${ }^{45}$ demonstrating that th overexpression of Runx2 in the late stage disfave is eoblast maturation. ${ }^{46,47}$ Animal models of calvarial recs. structio also confirmed this finding, demonstrating incre sed BMP2 expression as a result of combinational therapy.

Another advantage of this combinational n_ $\quad$, is the low cost and ease of accessibility. Unlike o mowth factors, NGF has abundant sources ${ }^{48}$ and NGF isolation and purification methods are well establishe an simpl for industrialization. Using the optimized three- cdure described herein, purified and bioactive NGF wa sily extracted from Chinese cobra venom. Simi arly, $\mathrm{CP}$ is also easily produced.

In conclusion, porous $2 \mathrm{P}$ combined with NGF exerts potent effect an steoblast differentiation and calvarial regeneration, and tho fects of combination treatment were superior to eit er, atmer alone. The results confirmed the neuroosteor actions in the promotion of osteogenesis and accelerat of bone formation.

\section{CONFLICT OF INTEREST}

The authors declare no conflict of interest.

\section{ACKNOWLEDGEMENTS}

This study was financially supported by the National Key Research and Development Program of China (grant no. 2016YFB0700804), the Guangxi Scientific Research and Technological Development Foundation (grant no. Guikegong 1598013-15) and the Guangxi
Science Fund for Distinguished Young Scholars (grant no. 2014GXNSFGA118006).

1 Chung SM, Jung IK, Yoon BH, Choi BR, Kim DM, Jang JS. Evaluation of different combinations of biphasic calcium phosphate and growth factors for bone formation in calvarial defects in a rabbit model. Int J Periodontics Restorative Dent 2016; 36: s49-s59.

2 Mangano C, Sinjari B, Shibli JA, Mangano F, Hamisch S, P telli A et al. A human clinical, histological, histomorphometrical and h raphic study on biphasic HA-Beta-TCP 30/70 in maxillary sinus aug tation. Clin Implant Dent Relat Res 2015; 17: 610-618.

3 Hu J, Yang Z, Zhou Y, Liu Y, Li K, Lu H. Porous bipha calcium hosphate ceramics coated with nano-hydroxyapatite and sodea h $m$-senchymal stem cells for reconstruction of radius segm ntal defects in abbits. J Mater Sci Mater Med 2015; 26: 257.

4 deGabory L, Delmond S, Deminiere \%, St $\mathrm{D}$, Bord nave L, Fricain JC. Assessment of biphasic calcium pho ate to nasal septum defects in sheep. Plast Reconstr Surg 2\%1; 1. 107-116.

5 Bodde EW, Wolke JG, Kowals' RS, Jansen Bone regeneration of porous beta-tricalcium phosphate (Co it TCP) and of biphasic calcium phosphate ceramic (Biosel) in trabecur. efects in sheep. J Biomed Mater Res A 2007; 82: 711-72

6 Farina NM, Guzon M, Pe a ML, Cantalapiedra AG. In vivo behaviour of two different biphasic nted in mandibular bone of dogs. J Mater Sci Mater Med 2008; 1565-1573.

7 Roldan JC, Bone forma rom degradation of a highly porous biphasic calcium phosphate ce anic , presence of BMP-7, VEGF and mesenchymal stem cells in an ectopic mouse model. J Craniomaxillofac Surg 2010; 38: 130.

Kjat Neuro-osteology. Crit Rev Oral Biol Med 1998; 9: 224-244.

Persso $E$, Lerner UH. The neuropeptide VIP potentiates IL-6 production 'uce $d$ by proinflammatory osteotropic cytokines in calvarial osteoblasts an. the osteoblastic cell line MC3T3-E1. Biochem Biophys Res Commun 2005; 335: 705-711.

Lerner UH, Persson E. Osteotropic effects by the neuropeptides calcitonin gene-related peptide, substance $P$ and vasoactive intestinal peptide. J Musculoskelet Neuronal Interact 2008; 8: 154-165.

11 Lomholt JF, Keeling JW, Hansen BF, Ono T, Stoltze K, Kjaer I. The prenatal development of the human cerebellar field in Down syndrome. Orthod Craniofac Res 2003; 6: 220-226.

12 Letic-Gavrilovic A, Piattelli A, Abe K. Nerve growth factor beta(NGF beta) delivery via a collagen/hydroxyapatite (Col/HAp) composite and its effects on new bone ingrowth. J Mater Sci Mater Med 2003; 14: 95-102.

13 Wang L, Cao J, Lei DL, Cheng XB, Zhou HZ, Hou R et al. Application of nerve growth factor by gel increases formation of bone in mandibular distraction osteogenesis in rabbits. Br J Oral Maxillofac Surg 2010; 48: 515-519.

14 Cao J, Wang L, Lei DL, Liu YP, Du ZJ, Cui FZ. Local injection of nerve growth factor via a hydrogel enhances bone formation during mandibular distraction osteogenesis. Oral Surg Oral Med Oral Pathol oral Radiol 2012; 113: 48-53.

15 Arumäe U, Neuman T, Sinijärv R, Saarma M. Sensitive time-resolved fluoroimmunoassay of nerve growth factor and the disappearance of nerve growth factor from rat pheochromocytoma PC12 cell culture medium. J Immunol Methods 1989; 122: 59-65.

16 Lipps BV. Biological and immunological properties of nerve growth factor from snake venoms. J Nat Toxins 1998; 7: 121-130.

17 Lipps BV. Detection of nerve growth factor (NGF) in venoms from diverse source: isolation and characterization of NGF from the venom of honey bee (Apis melifera). J Nat Toxins 2000; 9: 13-19.

18 Lipps BV. Isolation of nerve growth factor (NGF) from human body fluids; saliva, serum and urine: comparison between cobra venom and cobra serum NGF. J Nat Toxins 2000; 9: 349-356.

19 Lipps BV, Khan AA., Lipps BV. Antigenic cross reactivity among the venoms and toxins from unrelated diverse sources. Toxicon 2000; 38: 973-980.

20 Lipps BV. Isolation of subunits, alpha, beta and gamma of the complex taipoxin from the venom of Australian taipan snake (Oxyuranus s. scutellatus): characterization of beta taipoxin as a potent mitogen. Toxicon 2000; 38: 1845-1854. 
21 Mariam K, Tu AT. Extremely low nerve growth facior (NGF) activity of sea snake (Hydrophiidae) venoms. J Nat Toxins 2002; 11: 393-398.

22 Asanome A, Kawabe J, Matsuki M, Kabara M, Hira Y, Bochimoto $\mathrm{H}$ et al. Nerve growth factor stimulates regeneration of perivascular nerve and induces the maturation of microvessels around the injured artery. Biochem Biophys Res Commun 2014; 443: 150-155.

23 Chen WH, Mao CQ, Zhuo LL, Ong JL. Beta-nerve growth factor promotes neurogenesis and angiogenesis during the repair of bone defects. Neural Regen Res 2015; 10: 1159-1165.

24 Grills BL, Schuijers JA, Ward AR. Topical application of nerve growth factor improves fracture healing in rats. J Orthop Res 1997; 15: 235-242.

25 Wang L, Zhou S, Liu B, Lei D, Zhao Y, Lu C et al. Locally applied nerve growth factor enhances bone consolidation in a rabbit model of mandibular distraction osteogenesis. J Orthop Res 2006; 24: 2238-2245.

26 Dodla MC, Bellamkonda RV. Differences between the effect of anisotropic and isotropic laminin and nerve growth factor presenting scaffolds on nerve regeneration across long peripheral nerve gaps. Biomaterials 2008; 29: 33-46.

27 Lee JY, Lee JW, Schmidt CE. Neuroactive conducting scaffolds: nerve growth factor conjugation on active ester-functionalized polypyrrole. $J R$ Soc Interface 2009; 6: 801-810.

28 Lee JY, Bashur CA, Milroy CA, Forciniti L, Goldstein AS, Schmidt CE. Nerve growth factor-immobilized electrically conducting fibrous scaffolds for potential use in neural engineering applications. IEEE Trans Nanobiosci 2012; 11: 15-21.

29 de Boer R, Knight AM, Borntraeger A, Hebert-Blouin MN, Spinner RJ, Malessy MJ et al. Rat sciatic nerve repair with a poly-lactic-co-glycolic acid scaffold and nerve growth factor releasing microspheres. Microsurgery 2011; 31: 293-302.

30 Jin J, Limburg S, Joshi SK, Landman R, Park M, Zhang Q et al. Peripheral nerve repair in rats using composite hydrogel-filled aligned nanofiber conduits with incorporated nerve growth factor. Tissue Eng Part A 2013; 19: 2138-2146.

31 Zhang H, Wang K, Xing Y, Yu Q. Lysine-doped polypyrrole/spider si' protein/poly(l-lactic) acid containing nerve growth factor composite fiot for neural application. Mater Sci Eng C Mater Biol Appl 201 56: 564-573.

32 Chao X, Xu L, Li J, Han Y, Li X, Mao Y et al. Facilitation of regeneration using chitosan-beta-glycerophosphate-nerve orowt. "actor hydrogel. Acta Otolaryngol 2016; 136: 585-591.

33 Esfahani H, Prabhakaran MP, Salahi E, Tayebifard A, imipour AVR, Keyanpour-Rad $\mathrm{M}$ et al. Electrospun nylon 6/zin doped oxyapatite membrane for protein separation: mecranism of fo, $\mathrm{ng}$ and blocking model. Mater Sci Eng C Mater Biol op/ 2016; 59: 420-428.

34 Zhu XD, Zhang HJ, Fan HS, Li W, Zhang XD. 'fect of pr ase composition and microstructure of calcium phosphate ct ic $\mathrm{n}$-ticles on protein adsorption. Acta Biomater 2010; 6: 1' $\circ-1541$.

35 Wang J, Zhang H, Zhu X, Fan H, Fan $\sim X$. Dynamic competitive adsorption of bone-related proteins on calcum nosphate ceramic particles with different phase compostic nd mic rostructure. J Biomed Mater Res B App/ Biomater 2013; 1: 10 9-107).

36 Wang J, Chen Y, Zhy X, Y, Fan Y et al. Effect of phase composition on pro ein adsor $n$ and osteoinduction of porous calcium phosphate cerar in in mice.) Biomed Mater Res A 2014; 102: 4234-4243.

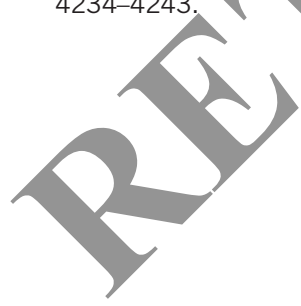

37 Alam I, Asahina I, Ohmamiuda K, Enomoto S. Comparative study of biphasic calcium phosphate ceramics impregnated with rhBMP-2 as bone substitutes. J Biomed Mater Res 2001; 54: 129-138.

$38 \mathrm{Kim} \mathrm{BS}$, Lee J. Enhanced bone healing by improved fibrin-clot formation via fibrinogen adsorption on biphasic calcium phosphate granules. Clin Oral Implants Res 2015; 26: 1203-1210.

39 Li XB, Chen MJ, Lei DQ, Yang B, Liao GS, Shu YY et al. Bioactivities of nerve growth factor from Chinese cobra venom. J Nat Toxins 1999; 8: 359-362.

40 Li XB, Liao GS, Shu YY, Tang SX. Brain delivery of bi Amylated NGF bounded to an avidin-transferrin conjugate. J Nat oxins 2000; 9: 73-83.

41 Benisch P, Schilling T, Klein-Hitpass L, Frey SP, Seefried L aijmakers N et al. The transcriptional profile of mesenchym 1 stem cell $p$ rations in primary osteoporosis is distinct and shows o xpressio or osteogenic inhibitors. PLOS ONE 2012; 7: e45142.

42 Hanai J, Chen LF, Kanno T, Ohtani-rujita N, Kir \%, Guo WH et al. Interaction and functional coopera on of PEBP2/CBF with Smads. Synergistic induction of the immuno bulin ge mline Calpha promoter. J Biol Chem 1999; 274: 3157 315

43 Javed A, Barnes GL, Jasany? BO, JL, Gerstenfeld L, Lian JB et al. runt homology domain transc otion fac (Runx, Cbfa, and AML) mediate repression of the bo ie loprotein promoter: evidence for promoter context-dependent ac ivity Cbfa proteins. Mol Cell Biol 2001; 21: 2891-2905.

44 Nishimura R tata Harris SE, Ikeda F, Yoneda T. Core-binding factor alpha 1 (Cbra nd Coblastic differentiation of $\mathrm{C} 2 \mathrm{C} 12$ cells without interactions with ad1 and Smad5. Bone 2002; 31: 303-312.

45 Jin P, ${ }^{1 / 1}, \mathrm{H}, \mathrm{Xu} \mathrm{G}$, . Mg L, Zhao J. Epigallocatechin-3-gallate (EGCG) as a pro-ost agen to enhance osteogenic differentiation of mesenchymal stem cells from numan bone marrow: an in vitro study. Cell Tissue Res 2014; 3. 6: 381-390.

- Iiu W, T, yosawa S, Furuichi T, Kanatani N, Yoshida C, Liu Y et al. erexpression of Cbfal in osteoblasts inhibits osteoblast maturation and ses osteopenia with multiple fractures. J Cell Biol 2001; 155: $7-166$

Cobb J, Dierich A, Huss-Garcia Y, Duboule D. A mouse model for human short-stature syndromes identifies Shox2 as an upstream regulator of Runx2 during long-bone development. Proc Natl Acad Sci USA 2006; 103: 4511-4515.

48 Kilmon J. Snake venom: 'gentler' purification provides attractive nerve growth factor source. Am Biotechnol Lab 1992; 10: 18-20.

(c) (1) () $\Theta$ This work is licensed under a Creative Commons Attribution-NonCommercial-NoDerivs 4.0 International License. The images or other third party material in this article are included in the article's Creative Commons license, unless indicated otherwise in the credit line; if the material is not included under the Creative Commons license, users will need to obtain permission from the license holder to reproduce the material. To view a copy of this license, visit http://creativecommons.org/licenses/by-nc-nd/4.0/ 